\title{
Heavy vaginal bleeding, post termination of pregnancy: not always retained products of conception
}

\author{
Vidhu Krishnan ${ }^{1,2} *$
}

\begin{abstract}
${ }^{1}$ Department of Obstetrics \& Gynaecology, King Edward Memorial Hospital, Subiaco-6008, Western Australia, ${ }^{2}$ Department of Obstetrics \& Gynaecology, Swan District Hospital, Perth-6056, Western Australia
\end{abstract}

Received: 23 January 2014

Accepted: 02 February 2014

\author{
*Correspondence: \\ Dr. Vidhu Krishnan, \\ E-mail: Krishnan.vidhu@yahoo.com.au
}

(C) 2014 Krishnan V. This is an open-access article distributed under the terms of the Creative Commons Attribution Non-Commercial License, which permits unrestricted non-commercial use, distribution, and reproduction in any medium, provided the original work is properly cited.

\begin{abstract}
Vaginal bleeding, post suction evacuation is a common presentation both to the emergency department and to general practitioners. Though the most common cause of vaginal bleeding, post-surgical evacuation is retained products of conception, a rare cause of catastrophic bleeding is uterine arteriovenous malformation (AVM). There are fewer than 100 cases of uterine AVM reported in the literature however, it is a potential life threatening condition and it is important for this differential to be considered when faced with a patient who presents with heavy vaginal bleeding. We describe a case of a 32 year old patient who presented to the emergency department with heavy vaginal bleeding, post termination of pregnancy, secondary to a uterine arteriovenous malformation who was managed expectantly.
\end{abstract}

Keywords: Uterine arteriovenous malformation, Vaginal bleeding, Uterine artery embolisation, Dilatation and curettage, Ultrasound

\section{INTRODUCTION}

Uterine AVMs are uncommon but known to be a cause of life threatening bleeding. The exact incidence of uterine AVM is not known but fewer than 100 cases have been reported in the literature. ${ }^{1-3}$ The usual presentation to the emergency department of a uterine AVM is heavy vaginal bleeding, usually with a background of intrauterine instrumentation like curettage or caesarean section. Historically, uterine AVMS were diagnosed in hysterectomy specimens but with advent of improved imaging facilities, it has been possible to diagnose the AVMs in a much more timely manner rather than just in hysterectomy specimens. Management options for uterine AVMs to a large extent are dependent on the patient's clinical situation and desire for fertility.
We describe the case of a 32 year old with a uterine AVM who was managed expectantly.

\section{CASE REPORT}

A 32 year old lady Gravida 5, parity 3 presented to the emergency department with heavy vaginal bleeding, postsurgical termination of pregnancy in a private hospital.

The patient was 16 weeks pregnant when she underwent the termination. Prior to this, she had had three normal vaginal deliveries and one previous termination 12 years ago.

She did not have any other significant medical history.

The procedure itself was uncomplicated. However following a period of observation, when the patient was 
in recovery room, heavy vaginal bleeding was noticed. She had started soaking through her pads. By the time, she was transferred to the emergency department, she had soaked through at least six maternity pads.

On examination, she was conscious, oriented and speaking in full sentences. Her blood pressure was 106/60 mm Hg, pulse 102 beats per minute and saturation $100 \%$ at room air. Abdominal examination showed mild tenderness in the suprapubic region. On per speculum, $300 \mathrm{ml}$ of clots were evacuated. Cervical os was noted to be open but with minimal active bleeding. Bimanual examination showed a uterus which was well contracted. Her investigations revealed a haemoglobin of $14.2 \mathrm{~g} / \mathrm{dl}$ and normal coagulation profile. Real time ultrasound in the emergency department revealed an empty uterus with no retained products; however a formal ultrasound in the radiology department showed an ovoid $19 \mathrm{~mm}$ X $23 \mathrm{~mm}$ anechoic space containing arterialised flow, appearances of which was consistent with an arteriovenous malformation. The scan also confirmed no retained products of conception.

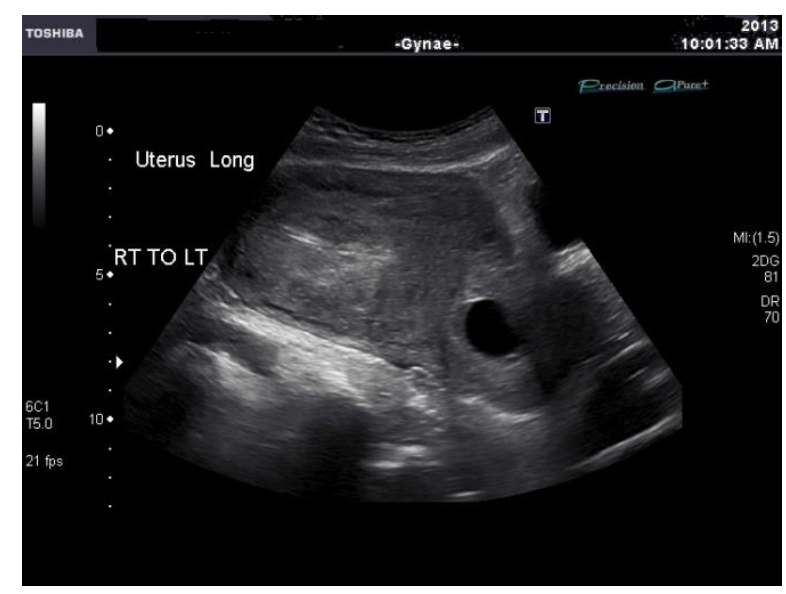

Figure 1: Ultrasonography of the long axis of uterus showing enlarged uterine cavity in the lower segment.

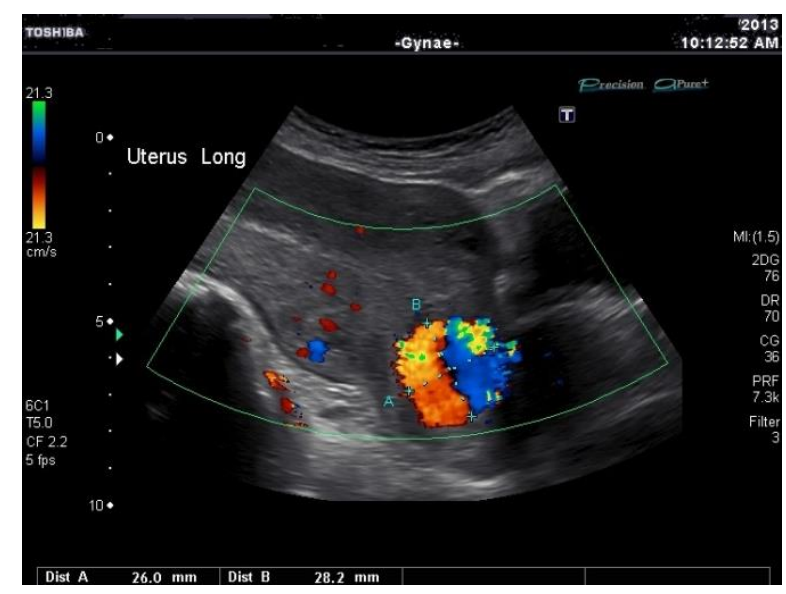

Figure 2: Doppler ultrasonography of uterus in long axis showing arteriovenous malformation in the lower segment.

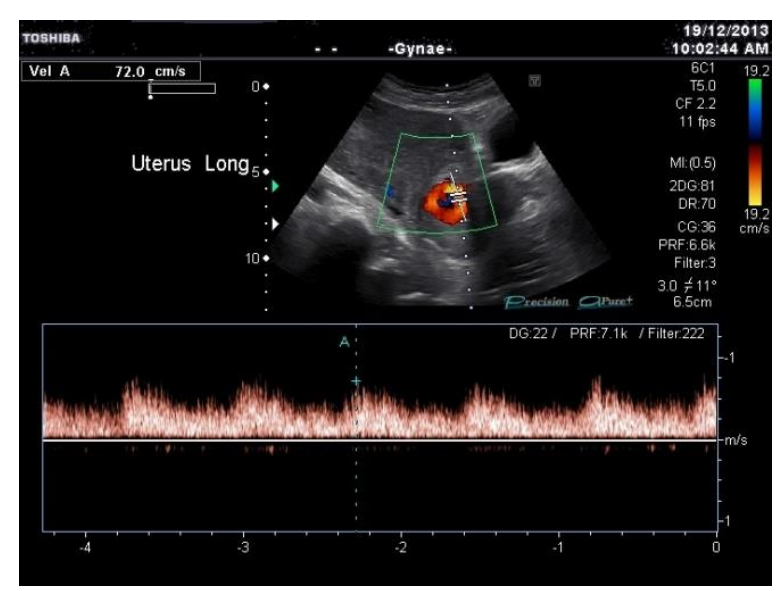

Figure 3: Doppler ultrasonography of uterus in long axis showing pulsatile flow in arteriovenous malformation.

Her initial bleeding settled but following a 24 hour period of observation, she had another episode of heavy bleeding which also surprisingly settled spontaneously. During her admission her vital signs were always stable but her haemoglobin dropped from $14.2 \mathrm{~g} / \mathrm{dl}$ to $8.1 \mathrm{~g} / \mathrm{dl}$.

The patient declined to have blood transfusion or iron infusion, preferred to be on iron supplements. Treatment options of uterine artery embolisation was discussed with her but as her bleeding had settled; patient chose to have a wait and watch policy and was eventually discharged on tranexamic acid.

She currently remains asymptomatic; two months post her initial presentation.

\section{DISCUSSION}

Uterine AVMs are abnormal vascular connections between arteries and veins which could be congenital or acquired. Congenital variety are usually present along with other systemic vascular connections. ${ }^{4}$ Acquired AVMs are usually seen following intrauterine procedures like curettage, caesarean section or gestational trophoblastic disease. ${ }^{4,5}$ In a systematic review by Peitsidis et $\mathrm{al}^{3}$, the mean age of women diagnosed with AVM was 30 years and all women were symptomatic and presented with acute heavy vaginal bleeding.

Ultrasound is readily available in most emergency and gynaecological departments hence initial evaluation of AVM is usually with ultrasound. In Gray scale ultrasound, uterine AVMs are seen as subtle myometrial heterogeneity, tubular sparse multiple spaces in the myometrium and color doppler and spectral studies demonstrate flow reversals and 'colour mosaic "pattern., Gray scale ultrasound by itself is nonspecific however addition of colour doppler and spectral studies increase accuracy of ultrasound imaging. Other imaging modalities used are MRI and CT, with angiography being considered as a gold standard. 
Treatment options for patients with uterine AVM range from medical management with combined oral contraceptive pill, danazol, intramuscular or oral methylergonovine maleate ${ }^{7}$ to uterine artery embolization, laparoscopic bipolar coagulation of uterine vessels and hysterectomy. ${ }^{11}$

Hysterectomy is the definitive treatment in case of symptomatic patients who no longer desire fertility. Currently, uterine artery embolization (UAE) forms the treatment of choice, in clinically stable patients desiring future fertility. Successful pregnancies have been known to occur after UAE. ${ }^{8,9}$

Expectant management is a viable option that can be offered to clinically stable patients in whom bleeding settled as discussed in the case report, as spontaneous resolution of uterine AVMs are known to occur. ${ }^{10}$ However, in patients who have been offered expectant management or medical management, it recommended that the patients have regular clinical follow up. ${ }^{11}$

The treatment of uterine AVM is governed by the clinical status and the patient's desire for fertility.

\section{ACKNOWLEDGEMENTS}

We are very thankful to the patient who has given her permission to use the ultrasound pictures.

Funding: No funding sources

Conflict of interest: None declared

Ethical approval: Not required

\section{REFERENCES}

1. Selby. Uterine arteriovenous malformation with sudden heavy vaginal hemmorhage. Western journal of emergency medicine. 2013;14(5):411-4.

2. Sellers F, Palacios-Marques A, Moliner B, Bernabeu R. Uterine arteriovenous malformation. BMJ case reports. 2013;2013.
3. Peitsidis P, Manolakos E, Tsekoura V, Kreienberg R, Schwentner L. Uterine arteriovenous malformations induced after diagnostic curettage: a systematic review. Archives of gynecology and obstetrics. 2011;284(5):1137-51.

4. Rosa e S. Conservative management of large uterine arteriovenous malformation: case report. Fertility and sterility. 2008;90(6):2406-7.

5. Capmas P, Levaillant JM, Teig B, Fernandez H. Uterine arteriovenous malformation involving the whole myometrium. Ultrasound in obstetrics \& gynecology. 2013;41(6):715-7.

6. Huang. Uterine arteriovenous malformations: Grayscale and Doppler US features with MR imaging correlation. Radiology. 1998 Jan;206(1):115-23.

7. Khatree. Medical treatment of a uterine arteriovenous malformation. The Australian and New Zealand journal of obstetrics and gynaecology. 1999;39(3):378-80.

8. Delotte. Pregnancy after embolization therapy for uterine arteriovenous malformation. Fertility and sterility. 2006 Jan;5(1):228-e6.

9. McCormick. Successful pregnancy with a full-term vaginal delivery one year after n-butyl cyanoacrylate embolization of a uterine arteriovenous malformation. Cardiovascular and interventional radiology. 2006;29(4):699-701.

10. Timmerman. Vascular malformations in the uterus: Ultrasonographic diagnosis and conservative management. European journal of obstetrics \& gynecology and reproductive biology. 2000;92(1):171-8.

11. Rosalie M Grivell, Kym M. Reid, Amy Mellor. Uterine Arteriovenous Malformations: A Review of the Current Literature. Obstetrical and gynecological survey. 2005;60(11):761-7.

DOI: $10.5455 / 2320-1770 . i j r \operatorname{cog} 20140361$

Cite this article as: Krishnan V. Heavy vaginal bleeding, post termination of pregnancy: not always retained products of conception. Int J Reprod Contracept Obstet Gynecol 2014;3:273-5. 